


\section{Los discursos, los actores y las prácticas en la atención migratoria en Latinoamérica*}

\section{Fernando Neira Orjuela**1}

\section{Resumen}

En las últimas décadas términos como gobernanza y gestión migratoria han cobrado fuerza en la elaboración e implementación de políticas públicas por parte de los diferentes países interesados en el tema. Se vuelve relevante mostrar las discusiones, los actores y las prácticas que generan tales conceptos, en la medida que es un hecho el enfrentamiento, político y social entre las ideas institucionales del control de migrantes con las de protección de los derechos de migrantes.

Palabras clave: migración; gobernanza; gobernabilidad; organizaciones sociales; gestión pública.

\section{The discourses, actors and practices in the treatment of migration in Latin America}

\section{Summary}

In the last decades terms such as migration governance and management have gained momentum in the drafting and implementation of public policies by various countries interested in the subject. It has become relevant to present the discourses, actors and practices that generate these concepts, to the extent that there is clear political and social confrontation between the institutional ideas around controlling migrants and those regarding the protection of migrants' rights.

Key words: migration; governance; governability; social organizations; public management.

\section{Discursos, atores e práticas para a atenção do fenómeno migratório na América Latina}

\section{Resumo}

Nas últimas décadas, expressões como governança e gestão migratória tomaram força na criação e implementação de políticas públicas em diferentes nações interessadas no assunto. Torna-se relevante mostrar os debates, os atores e as práticas que geram tais conceitos, porque é um fato de confrontação política e social entre as ideias institucionais de controle dos migrantes e as de proteção dos direitos dos expatriados.

Palavras-chave: migração; governança; governabilidade; organizações sociais; gestão pública.

Artículo de reflexión derivado de investigación. Este artículo hace parte de una investigación más amplia titulada: Migración andina indocumentada en Buenos Aires, Santiago de Chile y Sao Paulo: política pública y actores sociales. Proyecto enmarcado en la línea de investigación: Política economía y sociedad en América Latina y el Caribe. Responsable, Fernando Neira Orjuela, Financiado por el Consejo Nacional de Ciencia y Tecnología (CONACYT) de México. Proyecto terminado enjunio de 2019.

** Investigador Titular B definitivo del Centro de Investigaciones sobre América Latina y el Caribe de la Universidad Nacional Autónoma de México, México. Doctor en Estudios de Población por el Colegio de México. Línea de investigación; migración latinoamericana. Correo electrónico: ferneira@unam.mx ORCID: https://orcid.org/0000-0002-8118-4053 


\section{Los discursos, los actores y las prácticas en la atención migratoria en Latinoamérica}

\section{Introducción}

Con la transformación del Estado en los años ochenta hacia un modelo neoliberal, cambia la manera de atender las problemáticas políticas, económicas y sociales que ya no son vistas como responsabilidad exclusivamente de los Estados. La migración como un fenómeno creciente determinó la generación de discusiones, instituciones y acciones que han sido inspiradas la mayor de las veces en las leyes de mercado y en detrimento de los derechos de los migrantes. Debido a las implicaciones de los modelos de gobernanza y gestión migratoria que han imperado en el ámbito general y, para el caso de los problemas de orden y regulación de la movilidad humana en América Latina y el Caribe en particular, se hace relevante una recapacitación discursiva.

En este sentido, el objetivo del presente artículo es hacer una descripción de la literatura existente para mostrar los discursos, los actores institucionales involucrados, las prácticas desarrolladas, así como los retos que existen en la implementación de los modelos de gobernanza y gestión migratoria.

Para este fin, el documento se encuentra organizado en cuatro partes de la siguiente manera: en un primer momento, se presentan las discusiones relacionadas con los conceptos de gobernanza y gestión migratoria; en un segundo apartado, se da cuenta de los actores institucionales que han jugado un rol protagónico en la elaboración e implementación de estos discursos; en tercer lugar, se describen las prácticas que dichas instituciones han desarrollado para hacer efectivo, adaptarse y defenderse del modelo de gestión migratoria en el nuevo entorno económico; finalmente, se muestran algunos de los retos que implica asumir ese modelo de gestión migratoria a la luz de los derechos de los migrantes. 


\section{Los discursos}

En las últimas décadas, con el incremento de la dinámica migratoria a nivel internacional, la atención institucional de los flujos migratorios ha determinado discursos que pretenden consolidar la forma como debe ser atendida esta población.

En ese sentido, diversos autores como Guild y Grand (2017), Serna (2010), Rhodes (2007), Sánchez (2012) y Koiuman (2005), han discutido dos conceptos que han emergido como elementos explicativos para lo que debería ser el manejo de la migración: gobernanza (governance) y gestión (management).

En cuanto a la idea de la gestión migratoria, esta surge según Kron (2011) en la época posterior al fin de la Guerra Fría, cuando la migración tenía el potencial de generar una verdadera crisis y era necesario un régimen global y holístico de reglas y normas para enfrentar el fenómeno exitosamente. Para la autora, la gestión migratoria, por tanto, debería convertir la migración internacional en un proceso más ordenado, manejable y previsible; lo cual implicaba, simultáneamente, una apertura regulada en relación con los flujos benéficos y la continuación de las restricciones con respecto de la migración no deseada.

Es a inicios de los años noventa que se usó la categoría de gestión más formalmente en la migración por parte de Bimal Ghosh, para quien es una tercera vía instalada entre los libertarios y los controladores, o sea entre quienes piden migración sin fronteras y los que piden fronteras reguladas. Por eso, según Estupiñán (2013), opta por gestión y no por control, dado que para él la primera expresa de mejor forma la conjunción y/o armonización entre los dos extremos. En cuanto a la gobernanza y su incidencia en el campo de las migraciones, señala Estupiñán que su antecedente principal lo constituye la Comisión sobre Gobernanza Global (1993/94) en la que también tiene injerencia Ghosh. Destaca que gobernanza y gestión son términos cercanos e interdependientes que se han ido afinando entre las áreas de relaciones internacionales y de gestión empresarial. Ambos dispositivos, nos dice, hacen parte de la redefinición de la política, empleando técnicas de la empresa privada en la que participan las agencias internacionales en su calidad de "nuevos" actores. Un hecho preocupante con estas concepciones es que ello:

Implica que es la economía la que pasa a controlar al Estado y no a la inversa. En otras palabras, gestión y gobernanza son formas de gobierno requeridas por la economía neoliberal, esa que ha subsumido lo social bajo su manto, y la gubernamentalidad nombra, por tanto, su implementación. Teniendo en cuenta este punto inicial, notaremos que hay presupuestos, actores y técnicas que son los que permiten la instalación de formas específicas de gobierno de las migraciones (Estupiñán, 2013, p. 10) 
Desde esta concepción, Kron (2011) considera que la Organización Internacional para las Migraciones (OIM) es un organismo determinante de la política y los discursos de gestión, que articula un modelo basado en los tres pilares de Ghosh ${ }^{1}$, con lo cual forma parte de un nuevo tipo de gobierno internacional caracterizado por la externalización de la elaboración de políticas hacia agencias "privadas",

En contraste con el bien definido y legitimado mandato del Alto Comisionado de las Naciones Unidas para los Refugiados (ACNUR), la OIM es una organización situada fuera del sistema de las Naciones Unidas y sin un claro mandato. Sin embargo, la OIM juega un papel cada vez más influyente en las decisiones de los gobiernos; por medio de la producción de conocimiento, la asesoría "científica" o "técnica" a los estados y el desarrollo de programas, ya sea por encargo de los gobiernos o en forma directa, mediante la puesta en práctica de políticas. Por tanto, la OIM puede ser más bien descrita como una compañía transnacional privada que suministra servicios migratorios a los gobiernos. Dicho carácter se manifiesta también en su presupuesto, ya que recibe muy poco financiamiento permanente y depende de proyectos financiados, en su mayoría, por los estados metropolitanos receptores de migrantes, en particular Estados Unidos. (Kron, 2011, p. 59)

De esta manera la OIM ha pasado de ser en un organismo operativo logístico a convertirse en la Agencia para las Migraciones. Este nuevo rol adoptado en las últimas décadas le ha implicado, como dice Estupiñán (2013), la producción, o mejor, la adhesión de un modelo de gestión de las migraciones que está diseminando por todo el orbe. Esto es posible gracias a que cuenta con personal y con estrategias para asesorar gobiernos, instituciones y formuladores de políticas públicas.

Por tanto, se hace pertinente la crítica de esta autora para quien:

La gestión entonces es una vía aparentemente menos violenta para lograr la regulación y la contención de las migraciones, pues mientras se insiste en la defensa de los derechos humanos de los migrantes acorde con la normativa internacional, se vehiculizan los intereses de unas agendas y unos estados específicos... la gestión es un vehículo velado del control y la seguridad". El acento puesto en uno u otro depende de las problemáticas contextuales que se requieran enfrentar

1 Este autor considera necesario armonizar las necesidades e intereses de los países emisores, de tránsito y destino, así como de los propios migrantes, cumpliendo básicamente tres condiciones: la primera sería un compromiso entre países emisores y de entrada para, por un lado, reducir una migración desordenada y, por otro, brindar oportunidades para una entrada legal. En segundo lugar, ambos grupos de países deben adherirse a normas internacionales con parámetros consensuados que guíen su accionar; y, en tercer lugar, atender todos los tipos de flujos migratorios como el laboral, la reunificación familiar, el asilo y el refugio (Ghosh, 2005). 
(narcotráfico, terrorismo, trata de personas, etc.). Entonces libertad, seguridad y control es la triada gubernamental que rige las políticas migratorias y que están explícitas en la agenda de la OIM bajo los imperativos de ordenar, regular y predecir. (Estupiñán, 2013, p. 13)

Kron (2011) por su parte, coincide con la anterior crítica por lo que citando a Andrijasevic y Walters (2010), señala que la gestión migratoria está dominada por organizaciones intergubernamentales, en primer lugar, la OIM cuyo objetivo es enseñar estándares tecnocráticos occidentales a los países y a lo que llama los antiguos súbditos imperiales del Sur Global. De esta manera, para Kron (2011) el principal objetivo de la gestión migratoria consiste en alinear las políticas migratorias en regiones como África occidental o América Latina con los marcos normativos de control migratorio y las aspiraciones de ese Norte Global.

Aportando a esta discusión del papel proestatal que tienen en sus discursos de gestión migratoria algunas instituciones como la OIM, Geiger y Pécoud (2010), sostienen que el impacto de los organismos intergubernamentales es innegable, ya que a través de reportes e informes dirigen las discusiones internacionales a favor de la gestión y gobernanza migratoria desafiando, según los autores, la distinción entre la investigación académica e institucional respondiendo a modelos e ideas gerenciales donde tiene origen este término, que fue a la par con la aplicación de reformas neoliberales (desregulación, privatización, financiarización y libre comercio); por lo tanto, con una reestructuración productiva y normativa a nivel mundial que impactó multidimensionalmente la movilidad humana.

Existen otras perspectivas que abordan la gobernanza migratoria como una estrategia insuficiente, e incluso, contraproducente para atender las situaciones que surgen como consecuencia de los flujos migratorios. Janneth K. Clavijo y Silvana Santi (2009) consideran que las causas de la migración a gran escala comúnmente son obviadas al momento de negociar tratados internacionales, esto con la intención de controlar los flujos en sí mismos. Ello produce que las desigualdades existentes entre los territorios donde ocurren los fenómenos migratorios sean invisibilizadas, e inclusive, profundizadas. Esta situación hace, a decir de los autores, que los espacios de cooperación se tornen como mecanismos viables para el manejo de las migraciones, en función al ordenamiento y control pretendido, sin problematizar cómo estos espacios pueden ser reproductores de las relaciones de dependencia y dominación, intentando suprimir el conflicto al no cuestionar las asimetrías y desigualdades en el sistema internacional (Clavijo y Santi, 2009).

Por su parte Eduardo Domenech (2013), uno de los autores que más ha discutido el tema, cuestiona también esas ideas de gestión migratoria que desde diversas instituciones ha manejado la migración como vía alternativa para su securitización, pues considera que: 
Actúan imbricada o complementariamente en el presente momento histórico del capitalismo global. Es decir, las políticas de control con rostro humano integrarían el actual régimen global de control de las migraciones, cuyo despliegue también supone formas de regulación restrictivas, coercitivas y punitivas. Por otro lado, en términos analíticos, buena parte de la dificultad para dilucidar críticamente la configuración de dicho régimen de control migratorio y su extensión en el mundo radica en que tanto entidades nacionales como supranacionales que proclaman la importancia de la protección y defensa de los derechos de los migrantes justifican y validan al mismo tiempo, por acción u omisión, las medidas selectivas de visado, los rechazos en frontera, el uso de la biometría en los controles de ingreso y permanencia, los centros de internamiento de extranjeros y las deportaciones o expulsiones. (Domenech, 2013, p. 3)

Para el anterior autor, un modelo de gobernanza migratoria no sustentando en la securitización y más centrado en los derechos, debería ser el predominante en la región.

Sara Kalm (2010), aportando en dicho sentido crítico a los modelos imperantes de gestión migratoria, considera clave para lograr la eficiencia en los flujos migratorios tres elementos:

el primero, sería liberalizar pero gestionar movimientos, ya que las libertades producidas bajo el liberalismo deben ser organizadas y supervisadas, así que el interés en mejorar las técnicas de gestión y la cooperación internacional deben verse en este contexto; el segundo elemento, es el discurso político global sobre migración y desarrollo que se inclina por el incremento de un movimiento migratorio circular o temporal en vez de permanente, sobre todo, para migrantes poco calificados. El tercer punto es que esta gestión de la movilidad permite formar agentes de desarrollo donde los migrantes se convierten en un potencial capital humano que puede contribuir al desarrollo en sus países. (Kalm, 2010, p. 37)

La crítica que hace la autora hacia estos planteamientos de gestión migratoria se debe al desvanecimiento de las relaciones de poder que pueden articular de diversa manera los intereses de distintos grupos; muchas veces en detrimento de las personas que encarnan las profundas problemáticas y desafíos que implica migrar y que se relaciona en particular con migrantes en condición irregular, cuya complejidad requiere de una gestión más eficaz, justa y sensible a las condiciones sociales y problemas que presenta esta población.

Independiente de si hablamos de gobernanza o de gestión migratoria, es un hecho que los actuales modelos de manejo de la migración están más centrados 
en los intereses de los Estados que en los individuos y en discursos como los de la OIM, que tienen tanta injerencia en nuestra región. En la medida que las relaciones migratorias entre países expulsores y receptores están marcadas por desigualdades de poder, no es de extrañar que las políticas e instituciones internacionales que buscan regular esa relación prioricen los intereses de los segundos y que limiten los de los primeros.

Coincidiendo con esta preocupación, es decir, por la forma cómo a nivel internacional se viene manejando la política migratoria, Mármora (2010), señal que hay una crisis de gobernabilidad migratoria, ya que los Estados no cuentan con respuestas institucionalizadas ante los nuevos retos. Por eso el autor distingue al menos tres modelos de gobernabilidad migratoria que pueden adquirir diversos matices y contradicciones en la práctica: a) el modelo de securitización, donde básicamente el migrante es visto como una amenaza a la seguridad nacional, la irregularidad es sinónimo de ilegalidad criminalizando a este tipo de población; b) el modelo de los beneficios compartidos donde la migración ordenada y regular puede brindar beneficios tanto a países emisores como receptores, por lo que se inclina por las migraciones regulares; c) el modelo del desarrollo humano de las migraciones que coloca los derechos de las personas migrantes como el centro.

\section{Los actores}

Cuando se aborda la importancia de los actores de la gestión migratoria, aparecen diversas instituciones intergubernamentales y civiles jugando cada una un rol específico. Hay que comenzar por retomar el papel de la OIM cuya importancia discursiva para la gestión migratoria ya se señaló líneas atrás y, que la vuelve un actor preponderante ya que,

La función principal hasta 1989 fue la de ofrecer asistencia a las y los migrantes y refugiados, mientras que posterior al año 1989 su rol de asistente empieza a diversificarse. Éste incluye hacer las veces de secretaría técnica, para el caso de las Conferencias Regionales; ente capacitador, para los funcionarios públicos; ente consultor y asesor, para los elaboradores de políticas e impulsadores de campañas para el "beneficio de todos", entre otras tareas. La OIM pasa así de ser un organismo operativo logístico a ser la Agencia para las Migraciones. Este nuevo rol adoptado en las últimas décadas le ha implicado la producción, o mejor, la adhesión de un modelo de gestión de las migraciones que está diseminando por todo el orbe. Hecho posible gracias a que cuenta con personal y con estrategias para asesorar gobiernos, instituciones y formuladores de políticas públicas. Lejos de plantear sus programas como una obligación, su estrategia es la 
de agencia recomendadora y usa la bandera humanitaria como elemento incuestionable para lograr el consentimiento no sólo en los gobiernos "tercermundistas" o "en desarrollo", sino de la "sociedad civil" en general. Esta agencia lleva más de dos décadas instalando el discurso de la gestión y gobernanza de las migraciones a nivel global y por cerca de una década en la región sudamericana. (Estupiñán, 2013, pp. 11-12)

Además de la incidencia de la OIM como ya se vio, existen también otros actores no-estatales como organismos de la ONU, foros de discusión global y regional, el Banco Mundial, la OIT y ACNUR que han ganado una influencia creciente en la gestión migratoria. Otro actor importante que señala Kron (2011) son los "Procesos Consultivos Regionales sobre Migración" (PRCs) que son,

Foros informales o redes de actores gubernamentales y no gubernamentales. Su objetivo es discutir temas relacionados con la migración a un nivel regional o multilateral y crear nuevas alianzas entre los países involucrados en relación con la salida, el tránsito y la llegada de migrantes. Aunque los PRCs son no-vinculantes, la OIM los considera como los "actores" regionales más importantes en el área del "manejo de la migración intrarregional” y como un "instrumento" clave en el establecimiento de un nuevo régimen internacional migratorio.... [constituyen además] arenas decisivas en donde las relaciones entre actores gubernamentales y no gubernamentales son negociadas y las asimetrías, en términos de poder, son conciliadas entre los estados integrantes; de modo tal que las relaciones desiguales entre los estados metropolitanos y los estados del Sur Global, de donde vienen o por donde transitan los migrantes, son puestas en un nuevo marco de diálogo, asociación y cooperación. (p. 59)

Pese a la incidencia de estas instituciones, quizás uno de los actores no gubernamentales de mayor incidencia son las organizaciones civiles.

En América Latina, si bien desde mediados del siglo XX surgieron las primeras organizaciones sociales orientadas a dar respuestas a la temática migratoria, estas se multiplicaron desde los noventa, en un marco de fuertes críticas a la globalización neoliberal.

Esta mayor presencia de la sociedad civil en la discusión política sobre migraciones no ha sido un fenómeno exclusivo de esta región. Tal es así, que a nivel global se advierte un creciente impulso a la intervención de la sociedad civil por parte de diversos actores políticos: desde el Diálogo de Alto Nivel de Naciones Unidas, la Organización Internacional para las Migraciones (OIM) y la Secretaría General Iberoamericana (SEGIB), hasta la Comisión Global sobre las Migra- 
ciones Internacionales (GCIM) y el Foro Global sobre Migraciones y Desarrollo (GFMD), entre otros, quienes destacan la importancia de la participación de la sociedad civil en la discusión y elaboración de respuestas políticas sobre migraciones (Magliano, 2011, p. 10).

En un informe de la Comisión Global sobre las Migraciones Internacionales (CMMI) se indica que si bien los gobiernos siguen siendo los protagonistas principales en el ámbito de las migraciones internacionales, "muchos otros actores, entre ellos las autoridades locales, el sector privado, las ONG, las instituciones de la sociedad civil y las asociaciones de migrantes, están bien ubicadas para contribuir a la formulación y a la aplicación de políticas migratorias" (CMMI, 2005, p. 12).

Pero cuando hablamos de sociedad civil, nos referimos a un organismo no homogéneo donde lo que prevalece es la diversidad ya que se encuentra conformada por aquellas organizaciones y/o redes de organizaciones de migrantes, académicas, de la iglesia, de derechos humanos, vinculadas a la cuestión migratoria.

Un determinante fundamental por la que surgen las organizaciones civiles es a decir de Domenech (2008):

En respuesta a las complejas realidades migratorias contemporáneas y a las políticas instrumentadas por un amplio conjunto de los principales países receptores de población, sobre todo en los denominados países centrales, las cuales se han sustentado en visiones que tienden a restringir los procesos migratorios y criminalizar al migrante. En líneas generales, las organizaciones de la sociedad civil formulan demandas a los Estados y a los organismos internacionales a partir de un enfoque basado en los derechos humanos, reconociendo las asimetrías sociales, apuntando sus críticas a la globalización neoliberal y concibiendo a la migración y al migrante en términos de aporte, promoviendo la protección de los derechos de los y las migrantes, así como condenando las políticas restrictivas, la militarización de las fronteras, la criminalización de los migrantes en condición de irregularidad migratoria, el tráfico y la trata de personas, y la discriminación, xenofobia y racismo. (p. 9)

A principios de la década de 1990, el escenario de la organización de la sociedad civil se expandió y diversificó.

Las entidades autonombradas aparecen como tercer sector (más articulado para empresas y fundaciones), junto con las ONG ciudadanas, las militantes mismas, con un perfil ideológico definido y un proyecto político. Las últimas salen de la sombra, se ponen por delante e incluso en la vanguardia de los movimientos, convirtiéndose, en algunos casos, en instituciones autónomas y desconectadas de los 
movimientos. En la segunda mitad de la misma década, la situación económica cambió incluso más la dinámica de los movimientos sociales en general y de la gente en particular, así como de las ONG que repensaron sus planes, planes de acción, estrategias, formas de actuar, elaboración de planes estratégicos. etc. Se introdujeron nuevas directrices, como trabajar con los excluidos en cuestiones de género, etnia, edades, etc. (Gohn, 2013, p. 244).

Conforme la migración crece en el mundo en general y en la región latinoamericana en particular, esta se convirtió en una nueva bandera desde la que emergieron diferentes organizaciones civiles.

Magliano (2011), recuerda que a nivel regional, durante el Simposio sobre Migración Internacional en las Américas en Costa Rica, organizado por la OIM conjuntamente con la Comisión Económica para América Latina (CEPAL) y el Centro Latinoamericano y Caribeño de Demografía (CELADE), en el año 2000, comienza a esbozarse la importancia de la participación de la sociedad civil en el ámbito de discusión sobre las migraciones. En ese marco, Magliano (2011) refiere que se constituyó un foro simultáneo denominado "La sociedad civil: hacia nuevas formas de cooperación hemisférica en el tema migratorio", constituido por la Red Regional de Organizaciones Civiles para las Migraciones (RROCM), señalando que su objetivo principal era crear un espacio de discusión y concertación sobre políticas y acciones de las organizaciones de la sociedad civil con vistas a construir una agenda común.

El compromiso de las organizaciones civiles con los inmigrantes es muy amplio y serio. No solo les interesa la persona sino toda la complejidad de su situación y sabe articularse con todos los principales actores involucrados, la comunidad y el contexto local, el momento histórico y político.

Dentro de las organizaciones donde se evidencian estos compromisos señalados por la comunidad, se encuentran los denominados por Fox (2005) como organizaciones con membresía de base, que comprenden desde los clubes de oriundos y las asociaciones de migrantes, hasta organizaciones obreras y comunitarias. Considera que los migrantes, citando el caso norteamericano, han formado entre 600 y 2000 clubes o asociaciones en torno a sus comunidades de origen, no solo para realizar actividades sociales sino, también, para contribuir al mejoramiento de su comunidad. Sostiene que cada asociación tiene su núcleo duro, en forma de mesa directiva, compuesto generalmente por unas 10 o 20 personas; algunas disponen de una membresía amplia y de una capacidad para convocar cientos de familias (Fox, 2005). Destaca, asimismo, el hecho que los migrantes colectivos, en el proceso de salir a la luz pública, constituye un paso importante en el proceso de forjar una sociedad civil. Para este autor: 
La sociedad civil migrante tiene dos componentes principales. El primero, y más claro, está constituido por las organizaciones de base de los mismos migrantes. El segundo se halla delimitado con menor claridad porque sus fronteras no son tan precisas, pero consiste en organizaciones de la sociedad civil de Estados Unidos que, efectivamente, han sido transformadas por la participación y el liderazgo de los migrantes. Este proceso capta muchas parroquias católicas y congregaciones protestantes. También hay varias campañas para promover la participación de padres de familias en asociaciones escolares. (Fox, 2005, p. 46)

Por otro lado, dentro de las organizaciones civiles vale la pena destacar a las organizaciones religiosas, que desde sus iglesias se ocupan de cuestiones vinculadas a las migraciones en la región. Entre otras sobresalen,

El Consejo Episcopal Latinoamericano (CELAM), organismo de la Iglesia Católica que fue fundado en 1955 a partir de un pedido de los Obispos de América Latina y el Caribe y cuya sede está ubicada en Bogotá. A nivel de los países, en Argentina funciona desde 1951 la Comisión Católica Argentina de Inmigración (FCCAM), también se encuentra el Servicio Ecuménico de Apoyo y Orientación a Migrantes y Refugiados (CAREF), constituido por la iglesia Evangélica del Río de la Plata, la Evangélica Metodista Argentina, la Evangélica Discípulos de Cristo y la Diócesis Anglicana de Argentina, que desde 1973 trabaja por los derechos de los migrantes, refugiados y desplazados en general; en Chile, el Instituto Católico de Migración (INCAMI), creado en 1955, es una de las instituciones que ha promovido la implementación de una política pública explícita en materia de migraciones en ese país; en Bolivia, primero se constituye la Pastoral Migratoria en la década del setenta con el espíritu de atención al migrante y, a partir del 2001, se articula con la actual Pastoral de Movilidad Humana, teniendo como objetivo principal prestar servicio a los migrantes; en Brasil, el Serviço Pastoral dos Migrantes cumple un papel relevante en el tema migratorio, integrando el comité organizador del Foro Social Mundial de las Migraciones. En relación a las organizaciones de la sociedad civil que trabajan en torno la cuestión de los derechos humanos en la región, en 1992 se crea la Plataforma Interamericana de Derechos Humanos, Democracia y Desarrollo (PPDHDD) con el objetivo de promover una conciencia integral de derechos. Desde los noventa centra su interés en los derechos de los migrantes y, en relación a esto, se constituyó el grupo de trabajo sobre Migraciones y Derechos Humanos con el propósito de "sistematizar información, contribuir a la formulación de políticas e impulsar acciones y campañas a favor de los derechos de los y las migrantes en el continente. (Magliano, 2011, p. 12) 
Como se puede observar la sociedad civil es de gran importancia para una gestión migratoria no institucional, en defensa de las personas, de sus derechos, de sus necesidades.

\section{Las prácticas}

Se ha podido observar que la gestión migratoria ha determinado diversos discursos en donde sobresalen actores no estatales como la OIM, pero en particular, debe destacarse a las organizaciones civiles en sus distintas manifestaciones. Ahora es conveniente mostrar las prácticas, entendidas como acciones normativas, sociales y políticas que han desarrollado estas instituciones.

En el caso de la OIM, conviene retomar lo planteado por Kron (2011), para quien desde mediados de los años noventa, la actividad principal de la OIM consiste en la creación y coordinación, alrededor del mundo, de al menos quince denominados "Procesos Regionales Consultivos sobre Migración" (PRCs). Dentro de este contexto, señala que las técnicas propias del paradigma de gestión migratoria tales como el desarrollo de competencias, las campañas de información y los planes de acción contribuyeron a la transformación de los países de salida o de tránsito de migrantes en socios deficientes, pero en proceso de aprendizaje.

Kron (2011), considera a los PRCs como redes en donde la OIM puede alinear sus actividades con proyectos más amplios de gobernabilidad, desarrollo y ayuda regionales. En ese mismo sentido de injerencia regional la OIM, plantea como:

Ha estado presente en las Conferencias y Foros Mundiales así como en los Diálogos de Alto Nivel impulsados por la ONU para garantizar la inclusión del modelo de gestión migratoria en las agendas de trabajo. Es así como, producto de lo dispuesto en el Plan de Acción de la Conferencia sobre Población y Desarrollo que tuvo lugar en el Cairo, nacen los Procesos Consultivos Regionales que con la asistencia técnica de la OIM dan inicio en el subcontinente en 1996 (Proceso de Puebla) y en 1999 con el Encuentro Sudamericano sobre Migraciones, Integración y Desarrollo, que permitió la instalación de la Conferencia Sudamericana de Migraciones desde el año 2000. (Kron, 2011,p. 12)

Las prácticas de esta y otras instituciones, han sido la realización de campañas, de programas de retorno y readmisión de migrantes así como de refugiados, migración circular, vinculación de la diáspora e inversión productiva de las remesas

Un aspecto de incidencia de algunas instituciones es la parte normativa, desde la cual se ha venido trabajando en cuanto al derecho a la libre circulación, pero en donde existe una realidad apremiante, como es el hecho de que las enunciaciones 
de la Declaración de Derechos Universales, la ICRMW, o la Convención Internacional de Derechos Políticos y Sociales, no se aplican a cabalidad, con otro agravante y es que no todas las naciones las firman y las respetan. Todas las personas tienen el derecho a salir de cualquier país; sin embargo, las condiciones del trayecto, así como los requisitos y normativas para la entrada varían en cada país (Oficina del Alto Comisionado de Naciones Unidas para los Derechos Humanos [ACNUDH], 2012). Una de las propuestas de la gobernanza en la migración es de alguna manera estandarizar dichos requerimientos para facilitar y regular la movilidad humana.

En la medida que los lineamientos y las normativas de diversas instituciones internacionales se entrelazan y complementan, es necesario insistir en que el análisis debe detenerse en las formas en las que los Estados traducen e implementan dichas directrices en sus contextos, pero en particular, como ocurre en los contextos que reciben migrantes.

Frente a la complejidad y correlación de fuerzas que implica la relación de gobernanza con migración, acciones como los acuerdos bilaterales y regionales tienen también un peso estratégico importante para el ámbito latinoamericano. En este sentido, se puede mencionar la Conferencia Sudamericana sobre Migraciones (CSM) que tiene como antesala el Encuentro Sudamericano sobre Migraciones Integración y Desarrollo (1999) que cuenta con la cooperación técnica de la OIM. Dicho encuentro se llevó a cabo en Lima-Perú, donde se reunieron representantes de las naciones suramericanas preocupados por el incremento de los movimientos migratorios de las últimas décadas.

La Conferencia Sudamericana de Migraciones (CSM) es un foro de discusión y diálogo referente en las políticas migratorias de los países de América del Sur. En su Declaración de Principios Migratorios y Lineamiento Generales reconoce que la movilidad de las personas migrantes constituye un fenómeno sustancial de los procesos de integración económica, cultural y social entre los países, cuestión que demanda acuerdos multilaterales, además, presentan como una de sus convicciones:

[...] que se tiene la responsabilidad, en el marco de la reciprocidad histórica, de implementar políticas públicas orientadas a que la decisión de migrar, no migrar y retornar, sea verdaderamente voluntaria, informada y libre, que promueva la participación política, cultural y económica en las sociedades de origen y destino, que garanticen el ejercicio democrático y la inclusión social de nuestros ciudadanos y ciudadanas. (CSM, 2010, p. 3)

Es en este contexto donde se dan procesos, foros y acuerdos bilaterales o regionales que reflexionan e impactan las políticas en temas migratorios como por ejemplo la Comunidad de Estados Latinoamericanos y Caribeños (CELAC), el Mercado Común del Sur (Mercosur) y la Comunidad Andina (CAN). 
Del Mercosur hay que señalar su impacto importante en cuestiones de políticas migratorias como el Acuerdo de Residencia de Mercosur y asociados (Chile y Perú), que tiene como objeto la obtención de residencia legal temporal y permanente por parte de nacionales de los Estados parte en territorios de los Estados miembros y asociados del Mercosur. Dicho acuerdo reconoce:

Los derechos de los inmigrantes y de los miembros de sus familias como la igualdad de derechos civiles, la reunión familiar, el trato igualitario con nacionales, compromiso en materia previsional, el derecho a transferir remesas, así como el derecho de los hijos de los inmigrantes. Implícitamente podemos detectar en términos de gobernanza el interés de contar con un marco global de la política migratoria que permita un mayor control y gestión de los flujos que tiene como base el reconocimiento de los derechos humanos. (Zurbriggen y Mondol, 2010, p. 19)

En el caso de la Comunidad Andina de Naciones, sus miembros han facilitado la circulación de los ciudadanos, ya que se reconocen los documentos nacionales de identificación como único requisito para viajar en calidad de turistas. En el 2006 se aprobó el actual formato de la Tarjeta Andina de Migración que es un documento uniforme de control migratorio que permite un seguimiento estadístico de los movimientos entre los países andinos. Otro punto clave son las herramientas enfocadas en los trabajadores migrantes como el Instrumento Andino de Migración Laboral, de Seguridad Social y Seguridad y Salud en el Trabajo buscando la protección y asistencia a los ciudadanos andinos. Los Estados miembros de la CAN, son países emisores, por lo que también hay que prestar atención a los acuerdos bilaterales por ejemplo entre Brasil y Bolivia en 2005, 2006 y 2007 (Zurbriggen y Mondol, 2010).

Estos son algunos ejemplos de los acuerdos regionales para llevar a la práctica los nuevos desafíos de la movilidad humana y de agudas desigualdades económicas y sociales en tiempos de globalización.

De otra parte, hay que señalar la importancia del papel de las organizaciones civiles en la atención y apoyo de la población migrante, ya que terminan cubriendo las carencias de los gobiernos locales, así como regionales y, aunque en algunas ocasiones cuentan con el apoyo de instancias gubernamentales de atención a migrantes, se ven desbordadas por la complejidad el fenómeno migratorio y la falta de recursos.

Un punto indispensable al analizar las prácticas de la gestión migratoria es la falta de información sobre los derechos con los que cuenta dicha población, situación que a decir de Domenech (2008), acentúa el riesgo de caer en redes de explotación; además, hay sociedades que reproducen ideas xenófobas y racistas 
que dificultan una inserción digna del inmigrante en el lugar de destino. Para este autor, el trabajo constante y cercano con los inmigrantes da otra mirada sobre el fenómeno de movilidad humana y las consecuencias de la ineficacia operativa de las instituciones gubernamentales. Además, como se revisó a lo largo de este texto, el núcleo que se mantiene en el ámbito de la gobernanza, tiene que ver con un lenguaje de costo-beneficio económico que es matizado con el respeto a los derechos humanos, y contradicho al mismo tiempo, por medidas de securitización en las fronteras y la criminalización de la irregularidad migratoria Domenech (2008), en este sentido destaca que:

\begin{abstract}
El hecho de que diversas agencias internacionales, Estados nacionales u organizaciones de la sociedad civil promuevan o adhieran a un enfoque basado en los derechos humanos de los migrantes en contraposición a una visión de la política migratoria fundamentada en el control y la seguridad nacional que comete la falacia de asociar inmigración y terrorismo, cuya expresión más acabada la constituye la política migratoria estadounidense, no debería confundirnos: a través de fórmulas políticas basadas en la noción de migration management se aceptan como dadas las reglas y mecanismos del sistema económico internacional y se legitiman las nuevas formas de exclusión que produce, manteniendo la división entre migrantes "deseables" e "indeseables". (p. 69)
\end{abstract}

Lo interesante, y poco conocido, es que la acción colectiva se da a pesar de tantos obstáculos y los migrantes organizados están ocupando espacios públicos. Para Fox (2005), quien toma como referencia a Estados Unidos, algunos migrantes, y también algunas organizaciones comunitarias y religiosas, se incorporan en las organizaciones del país del norte de la clase obrera migrante multinacional y multiétnica. Pero quizás el accionar más importante que considera de las organizaciones de migrantes, es la toma de espacios, por lo que para el autor los clubes son solo una de las vertientes de la sociedad civil migrante, en la que también están las organizaciones obreras, religiosas e indígenas. Destaca en California a las Líderes Campesinas, una organización de base de defensa de los derechos de las mujeres jornaleras, principalmente migrantes quienes ocupan los espacios públicos de los pequeños pueblos rurales, con lo cual crean nuevos espacios públicos. De esta forma al tomar las calles, rompen la frontera entre lo público y lo privado, por ejemplo, en su lucha contra la violencia intrafamiliar (Fox, 2005).

\title{
Retos
}

Planteada la incidencia de los discursos, los actores y las prácticas en gestión migratoria regional, conviene ahora plantear los retos que vienen. En primer lugar, 
es necesario contar con una gestión migratoria que tenga una mayor preocupación por los migrantes, como personas, como seres humanos, como trabajadores, por lo que hay que:

Prevenir la explotación de los trabajadores migrantes y garantizar su contribución positiva a las sociedades de acogida y de origen exige una gobernanza de la migración laboral equitativa y eficaz en todos los niveles, y las instituciones nacionales del mercado de trabajo desempeñan una función importante en tal sentido. El sistema de gobernanza es más eficaz cuando los servicios públicos de empleo, los ministerios de trabajo, las empresas y las organizaciones de empleadores y de trabajadores son sólidos y todos los interesados tienen la capacidad para contribuir al diálogo nacional. Esto puede mejorar la confianza pública y apoyar las políticas de migración laboral. (OIT, 2017, p. 27)

De acuerdo a la OIT, la inspección del trabajo y el acceso a la justicia real y efectiva se presenta como un desafío que requiere el diálogo social ${ }^{2}$, de la cooperación internacional y un claro establecimiento de las obligaciones jurídicas de los Estados para lograr consenso y control migratorio eficiente.

Otro ejemplo, en esta preocupación por la gobernanza efectiva, es el informe de la Comisión Mundial sobre Migraciones Internacionales de Naciones Unidas (CMMI) publicado en octubre del 2005 titulado: Migración en un mundo interconectad: nuevas direcciones para la acción, en el cual se indica que existen al menos cuatro desafíos particulares en la gobernanza nacional de las migraciones internacionales;

La primera, sería la falta de coherencia, ya que la migración debe constituir una parte de la economía nacional de cada país y por tanto debe contemplarse dentro de los planes de desarrollo, así que sugiere definir objetivos claros para sus políticas migratorias. Un segundo punto, sería justamente la coordinación entre la formulación de políticas y su implementación, problemática que parte de una comunicación adecuada entre los gobiernos y otros actores como el empresarial y la sociedad civil; el tercer punto, es la capacidad real de los gobiernos en términos administrativos, de conocimientos y

2 "El diálogo social constituye el núcleo del mandato de la OIT y se considera fundamental para «la elaboración de una legislación y unas políticas transparentes y coherentes sobre migración laboral basadas en los derechos, que tengan en cuenta las necesidades del mercado de trabajo» [...en un] Estudio General de 2016, la Comisión de Expertos en Aplicación de Convenios y Recomendaciones (CEACR) reconoció «la función primordial» que desempeñan los interlocutores sociales en la gobernanza eficaz de la migración laboral, entre otras cosas «en relación con la elaboración, la aplicación y la adaptación continua de la legislación y la política en lo que respecta a la regulación de la migración laboral y a la promoción de la igualdad de oportunidades y de trato de los trabajadores migrantes»” (OIT, 2017, pp. 28-29). 
de presupuesto para lograr los objetivos propuestos; el cuarto reto tiene que ver con la cooperación entre estados ya que al tener una migración transnacional, es necesario una legislación y políticas con esta perspectiva. (CMMI, 2005, p. 75)

También, desde instituciones como la Oficina del Alto Comisionado para los Derechos Humanos (ACNUDH) se recuerda que la Comisión Mundial sobre las Migraciones Internacionales estuvo integrada por diecinueve miembros y realizó una serie de recomendaciones sobre la migración irregular, el impacto económico de la migración, la integración y la protección de los derechos humanos de los migrantes, todas ellas relacionadas con el interés de un mejor funcionamiento y coherencia de la gobernanza de la migración internacional. Estas reflexiones se retomaron en el primer Diálogo de Alto Nivel sobre la Migración Internacional y el Desarrollo realizada en el 2006, que fue la antesala del Foro Mundial sobre Migración y Desarrollo (FMMD) celebrado anualmente hasta la fecha y que,

representa uno de los principales espacios de interlocución y establecimiento de líneas generales entre los Estados y las organizaciones civiles sobre el fenómeno migratorio. El FMMD tiene un estrecho vínculo con el Grupo Mundial de Migración que aglutina a diversas figuras relacionadas con este tema como ACNUR, la Organización Internacional sobre Migraciones, Organización Internacional del Trabajo, el Programa de Naciones Unidas para el Desarrollo, entre otras. (ACNUDH, 2012, p. 25)

Frente a estos esfuerzos de organización y transversalidad, recientemente el Bloque Latinoamericano emitió siete recomendaciones al FMMD, ya que, de acuerdo a este documento la sociedad civil de la región latinoamericana se encuentra aún muy al margen de las discusiones globales respecto a los marcos de referencia mundiales para sentar las bases de la política migratoria global. Dichas recomendaciones tienen que ver en términos generales con una participación coherente y transparente por parte de los Estados, ampliar los espacios de reflexión y discusión sobre este fenómeno, así como incentivar una participación real de la sociedad civil. Además, afirman que el FMMD debe guardar una estrecha relación con los Objetivos del Desarrollo Sostenible ${ }^{3}$, así como reconocer la importancia de fortalecer la gestión y legislación de los gobiernos locales para asegurar el acceso a derechos e integración de los migrantes, ya que como mencionan, es el primer rostro con el que se encuentra dicha población (Estudios Fronterizos, 2017).

3 Aprobada en 2015 encabezada por la ONU, los 17 Objetivos de Desarrollo Sostenible de la Agenda 2030 para el Desarrollo Sostenible, se establecen con el interés de, a través de alianzas, reducir la pobreza, el hambre, la desigualdad económica, laboral, educativa y de género; así como luchar contra el cambio climático a través de acciones en la producción, consumo y reducción de contaminantes. Aunque no son jurídicamente obligatorios, sí intentan ser un referente en los marcos nacionales. 
Ramos (2015), por su parte, señala que el problema es la ausencia de una gobernanza eficaz, nacional y transfronteriza, así como las limitaciones de la interpretación institucional y jurídica. Plantea que un proceso de gobernanza sería el marco para integrar las demandas de los actores y las dimensiones del fenómeno migratorio. Por lo tanto, según este autor, lo que hace falta es un modelo de gestión, un esquema de cooperación y eficacia institucional con un enfoque de respeto a la legalidad orientado hacia la seguridad y el desarrollo, entrelazando las reglamentaciones a través del consenso, la operatividad y capacidad de negociar los aspectos sociales con una visión a largo plazo. Además, reitera que el Estado requiere mayor cooperación y coordinación con las organizaciones de la sociedad civil para desarrollar modelos de intervención pública y mecanismos de vigilancia y contraloría social. En este sentido, se coincide con el autor cuando refiere que se debe profundizar en el papel del Estado y la gestión en beneficio de la población migrante en general y los que presentan condición de irregularidad en particular, en jurisdicciones concretas como las ciudades, donde se hace necesario lograr el alcance real de todo este aparato discursivo e intersectorial sobre la gobernanza.

Recientemente, gran parte de los países adscritos a la ONU han firmado el Pacto Mundial para una Migración Segura, Ordenada y Regular (2018), el cual pretende crear un marco de acción que permita abordar los movimientos migratorios transnacionales desde una perspectiva no restrictiva, sino que tome en cuenta la multidimensionalidad del fenómeno y la responsabilidad internacional para atender dichos flujos. Este acuerdo pretende evitar que la migración sea tratada como un problema que debe eliminarse o reducirse, sino que debe ser encausada y protegida para inhibir la vulnerabilidad de quienes se trasladen de un territorio a otro. Por lo valioso de este instrumento jurídico internacional, el reto sigue siendo el que se pueda aplicary hacer respetar, pero en especial, que los derechos humanos de los migrantes no estén por debajo de los intereses de los estados receptores.

\section{Conclusiones}

El objetivo del presente artículo fue hacer una descripción de la literatura existente para mostrar los discursos, los actores institucionales involucrados, las prácticas desarrolladas, así como los retos que existen en la implementación de los modelos de gobernanza y gestión migratoria. En ese sentido es pertinente destacar algunos elementos planteados.

El incremento de los flujos migratorios en el mundo ocurre en el marco de la implementación del modelo neoliberal que da prioridad a los intereses económicos, lo cual conlleva a una preocupación por el control de los flujos poblacionales. Surgen entonces conceptos como gobernanza y gestión migratoria, que serán determinantes en los planteamientos de regulaciones y normas que se siguieron. 
Independiente de la prevalencia de un concepto sobre otro, lo cierto es que han sustentado el establecimiento de controles y regulaciones de las migraciones en beneficio de los intereses económicos de las naciones desarrolladas, quedando en un segundo plano la defensa de los derechos sociales de los migrantes de los países expulsores. De esta manera, prevalecen las ideas asociadas a la seguridad y el control, desde las cuales se construye gran parte de las políticas migratorias que tienen como propósito el sometimiento, la conducción y el gobierno discrecional institucional de la movilidad. Son diversas las críticas de autores sobre las concepciones de gobernanza y gestión migratoria, por considerar que tienen un carácter técnico y económico que las alejan de la realidad social del fenómeno migratorio y que se establecen desde relaciones desiguales de poder.

Por otra parte, la gestión migratoria ha consolidado la participación de los actores gubernamentales para su promoción y aplicación, como es el caso de la Organización Internacional de la Migraciones (OIM), así como también de las organizaciones de la sociedad civil que trabajan por los derechos de los migrantes. En primer término, la OIM ha consolidado y difundido de manera influyente el discurso de gestión migratoria en las agendas a nivel mundial, nutriendo esa política sustentada en la relación migración-seguridad, donde se prioriza el interés por la regularización, el ordenamiento y la eficiencia de la gestión migratoria, en especial la irregular, a favor de los países receptores.

No se pueden entender los modos y las lógicas del manejo de la migración internacional y sus manifestaciones regionales y nacionales, si no se considera el papel jugado por la sociedad civil, quien han liderado los procesos de intervención y mediación y defensa de derechos de distintos actores sociales con el Estado, como es el caso de los migrantes. Su compromiso social con los derechos humanos, su vocación crítica a las políticas gubernamentales que afectan los intereses personales de los migrantes y asociaciones, así como la atención de demandas de este sector de la población, los convierte en baluartes indispensables en la búsqueda verdaderas políticas migratorias.

En el caso de las prácticas que determina la gestión migratoria, no las podemos entender fuera de lo que son los discursos y actores involucrados. Los organismos gubernamentales han trabajado en la realización de campañas, programas de retorno y readmisión de migrantes y refugiados, migración circular, vinculación de la diáspora, inversión productiva de las remesas, políticas de control, acuerdos regionales para llevar a la práctica los nuevos desafíos de la movilidad humana y marcos normativos de regulación migratoria. En la sociedad civil siempre ha sido evidente el carácter de intervención directa en programas, acciones y servicios de apoyo a migrantes, así como denuncias contra las redes de explotación, la violación de derechos humanos, y las ideas xenófobas y racistas. Es una militancia activa lo que las caracteriza. 
Finalmente, en relación con los retos es claro que, si bien se ha avanzado mucho en cuanto a la construcción de una gestión migratoria, son notorias las carencias que prevalecen, no solo para que sea más propositiva, sino también para dirigirla a relaciones más igualitarias en beneficio de las personas migrantes, y no hacia las economías y los países.

Otro punto de discusión está en el alcance real de todo este aparato discursivo e intersectorial que se ha construido en los últimos tiempos sobre la gestión migratoria, siendo necesario preguntarse ¿A qué niveles se presenta? ¿Con qué grado de independencia de los apoyos estatales y de sectores económicos? ¿A qué nivel de respeto con los derechos humanos? Es la condición de "autonomía", de independencia institucional y política de la gestión migratoria, lo que sigue siendo parte de esa discusión, sobre lo cual la literatura existente no ha agotado las respuestas $y$, por el contrario, invitan como es el caso de este documento, a formular nuevas explicaciones, en particular desde el tema de los derechos humanos.

En un momento en el que los flujos migratorios se incrementan y diversifican constantemente, donde en muchas regiones la migración irregular ha desbordado la capacidad política y social de atender esta población, configurando una crisis de gobernabilidad migratoria, el tema de la gestión efectiva, no discursiva y de derechos humanos aparece como elemento clave en los diálogos a futuro de la política pública en este campo.

\section{Referencias bibliográficas}

Alto Comisionado de las Naciones Unidas para los Refugiados (ACNUR). (2005). Observación General № 6: Trato de los menores no acompañados y separados de su familia fuera de su país de origen. Ginebra: ONU. Recuperado de http://tbinternet. ohchr.org/_layouts/treatybodyexternal/Download.aspx?symbolno=CRC\%2fGC $\% 2 \mathrm{f} 2005 \% 2 \mathrm{f} 6 \&$ Lang=en

Clavijo, J y Santi, S. (2009). El Estado argentino y la emigración: cooperación, gobernabilidad y reciprocidad. En Domenech, E. (comp.), Migración y política: el Estado interrogado. Procesos actuales en Argentina y Sudamérica. (pp.167-199). Córdoba: Universidad Nacional de Córdoba.

Comisión Mundial sobre las Migraciones Internacionales (CMMI). (2005). Las migraciones en un mundo interdependiente: nuevas orientaciones para actuar. Recuperado de https://www.unav.edu/documents/4889803/4445a271-b02a-44d4-b0e5$887 \mathrm{dc5ab516f}$

Conferencia Sudamericana de Migraciones (CSM). (2010). Plan Sudamericano de Desarrollo Humano de las Migraciones, Contexto y Perspectivas. Bolivia. Décima Conferencia Sudamericana de Migraciones. Recuperado de: https://www.iom.int/ 
files/live/sites/iom/files/What-We-Do/docs/Plan-Sudamericano-de-DesarrolloHumano-de-las-Migraciones-PSDHM-2010.pdf

Domenech, E. (2008, septiembre). Migraciones internacionales y Estado nacional en la Argentina reciente. De la retórica de la exclusión a la retórica de la inclusión. Trabajo presentado en el III Congreso de la Asociación Latinoamericana de Población, ALAP, Córdoba, Argentina.

Domenech, E. (2013). "Las migraciones son como el agua": Hacia la instauración de políticas de "control con rostro humano". La gobernabilidad migratoria en la Argentina. Polis. Revista Latinoamericana, (35), 1-16. Recuperado de https:// journals.openedition.org/polis/9280

Estudios Fronterizos. (2017). Recomendaciones del Bloque Latinoamericano al Foro Mundial sobre Migración y Desarrollo 2017. Grupo de Investigación sobre Fronteras y Migraciones UACM. Recuperado de https://estudiosfronterizos. org/2017/06/29/recomendaciones-del-bloque-latinoamericano-al-foro-mundial-sobre-migracion-y-desarrollo-2017/

Estupiñán, M.L. (2013). Acerca de la gobernanza y la gestión migratoria. Crítica del papel de la OIM en el gobierno de la migración internacional y regional. Buenos Aires: CLACSO.

Fox, J. (2005). Repensar lo rural ante la globalización: la sociedad civil migrante. Migración y Desarrollo, (5), 35-58.

Geiger, M. y Pécoud, A. (2010). The Politics of International Migration Managment. En Geiger, M. y Pécoud, A. (eds.), The Politics of International Migration Management (pp. 1-20). UK: Palgrave Macmillan.

Ghosh, B. (2005). Managing Migration: Whither the Missing Regime?. Ginebra: UNESCO.

Global Commission on International Migration. (2005). Immigration in an interconnected world: new directions for action. Report of the global commission on international migration. Switzerland: The Global Commission on International Migration. Recuperado de: https://www.unitar.org/ny/sites/unitar.org.ny/files/ GCIMReport $\% 20$

Gohn, M. da G. (2013). Sociedade Civil no Brasil: movimentos sociais e ONGs. Revista Meta: Avaliação, 5(14), 238-253. Recuperado de http://revistas.cesgranrio.org. $\mathrm{br} /$ index.php/metaavaliacao/article/view/145

Guild, E. y Grant, S. (2017). Migration Governance in the UN: What is the Global Compact and What does it mean?. School of Law Legal Studies Research Paper, 252, 1-16.

Kalm, S. (2010). Liberalizing Movements? The Political Rationality of Global Migration Management. En Geiger, M. y Pécoud, A. (eds.), The Politics of International Migration Management (pp. 21-44). UK: Palgrave Macmillan.

Kalm, S. (2012). Global Migration Management, Order and Access to Mobility. En Geiger, M. y Pécuod, A. (eds.), The New Politics of International Mobility. Migration Management and its Discontents (pp. 49-73). Alemania: Universität Osnabrück. 
Kron, S. (2011). Gestión migratoria en norte y Centroamérica: manifestaciones y contestaciones. Anuario de Estudios Centroamericanos, 37, 53-85.

Magliano, M.J. (2011, agosto). Sociedad civil, migraciones internacionales y gobernabilidad. En la agenda política sudamericana. Ponencia presentada en el XXVII Congreso de la Asociación Latinoamericana de Sociología. VIII Jornadas de Sociología de la Universidad de Buenos Aires, ALAS, Buenos Aires.

Mármora, L. (2010). Modelos de Gobernabilidad Migratoria. La perspectiva política de América del Sur. REMHU - Revista Interdisciplinar da Mobilidade Humana, 18(35), 71-92.

Oficina del Alto Comisionado de Naciones Unidas para los Derechos Humanos (ACNUDH). (2012). Migración y derechos humanos. Mejoramiento de la gobernanza basada en los derechos humanos de la migración internacional. Ginebra: ONU.

Oficina Internacional del Trabajo (OIT). (2017). Informe IV Migración laboral: nuevo contexto y desafíos de gobernanza. Ginebra: OIT.

Ramos, J.M. (2015). La política migratoria mexicana y la seguridad fronteriza con Estados Unidos: cambio y continuidad, 2012-2014. Región y sociedad, (64), 351-382.

Rhodes, R. (2007). Understanding Governance: Ten Years On. Organization Studies, $8(8), 1243-1264$.

Sánchez, J.J. (2012). Usos de los conceptos de gobernabilidad y gobernanza (una manera de diferenciarlos). En Lerner, B., Uvalle, R. y Moreno, R. (coords.), Gobernabilidady gobernanza en los albores del siglo XXI y reflexiones sobre el México contemporáneo (pp. 217-265). México: Instituto de Investigaciones Sociales, UNAM; Instituto de Administración Pública del Estado de México, A.C.

Serna, J.M. (2010). Globalización y gobernanza: las transformaciones del Estado y sus implicaciones para el derecho público (contribución para una interpretación del caso de la Guardería ABC). México: Instituto de Investigaciones Jurídicas, UNAM

Zurbriggen, C. y Mondol, L. (coords.). (2010). Estado actualy perspectivas de las políticas migratorias en el MERCOSUR. Montevideo: FLACSO Uruguay. 